\title{
Higher Education and Solidarity? The Integration of Refugee Students at Austrian Universities
}

\section{Dimitri Prandner ${ }^{1,2}$, Robert Moosbrugger ${ }^{2}$}

${ }^{1}$ Department for Sociology and Political Science, Paris Lodron, University of Salzburg, Austria, ${ }^{2}$ Department for Sociology - Empirical Social Research Unit, Johannes Kepler University of Linz, Austria.

\begin{abstract}
The refugee streams of 2015 had a tremendous impact on European societies. In context of the influx of refugees, civil society showed large solidarity. Universities did so as well, organizing programs to accommodate asylum seekers and refugees on campus. As solidarity is necessary for social relationships and coordinating life chances in a just way, the effectiveness of such programs can only be understood, when insight into refugee students' opinions on such programs are analyzed.

In this article the case example of the Austrian MORE initiative is used to tackle the question what kind of bonds refugee students see between themselves, the universities and the goal to become part of their new host societies. Results show that refugee students are in danger of not being recognized, either because of their legal status or lack of opportunities and migrant sceptic surroundings.

Programs like MORE - and universities in general - may contribute to lessen these effects.
\end{abstract}

Keywords: Integration; Refugee Students; Asylum Seekers; Higher Education; Solidarity; Austria. 


\section{Introduction - Asylum Seekers, Refugees and Higher education?}

Since the 'long summer of migration' in 2015 the topic of refugees and asylum is a key driver in shaping the societal discourse around the world, dividing many countries on ideological and political fault lines (Hess \& Kasparek, 2017). The European governments seemed neither ready nor prepared to deal with the more than 1.3 million migrants that moved across the continent that summer, and in the absence of adequate infrastructure provided by the states, civil society and different institutions showed solidarity towards newly arriving refugees (for Austria see Meyer \& Simsa, 2018). This is also true for universities around Europe who rallied quickly to organize programs to integrate refugees into their structures. The scope of those offerings ranged from international, national, to institutional initiatives, set up by individual universities. These included policies to mitigate financial issues - e.g. waving tuition fees, getting aid for regular expenses -, as well as organizational barriers - ranging from credit transfer to program certification - and social issues - e.g. language or cultural barriers. Some of those efforts were tied to long running, best practice programs like DAFI - the Albert Einstein German Academic Refugee Initiative - sponsored by the UNHCR, while others were more specifically tailored to national or even university level demand (for an overview see Streitwieser et al., 2018). Among those is the Austrian MORE initiative - a unique, national program - that provides solidarity to those who were displaced and aims to help refugees to ingrate into the new host society. This is a particular interesting case as Austria is traditionally seen as a foreign-sceptic country, where it is hard to integrate (Bacher, 2017). In accordance, Bacher et al. (2019) showed in the context of higher education in Austria that integration not only depends on characteristics of refugee students but on societal attitudes towards refugees as well, as their needs go beyond those of regular students who want vocational education or need support to complete certain substantive goals. Perceptions and struggles accompanying this integration process will be explored in the following pages. Section 2 discusses the theoretical framework, section 3 describes the case study and data used, 4 presents the results and a discussion section 5 closes the article out.

\section{Solidarity as a concept?}

The question of solidarity has been long central to sociology, explaining and accounting for the creation of social relationships. In classic sociology, Emilé Durkheim understood solidarity as the forces that bind societies together either by shared beliefs and commonalities or the necessities of a highly differentiated division of labor (Durkheim, 1997). His contemporary, Max Weber (2006), additionally argued that solidarity is the product of affective bonds and common goals, which can be seen as social and political solidarity, respectively. In positing solidarity as the bonds of modern societies, Durkheim and Weber constructed explanations that are looking at bonds after they materialized, implying that there must be situations where social bonds do not yet exist. Thus, their formation must be seen as 
a societal process that is shaped by agency. Ipso facto solidarity is a "recurrent specification of social bonds with a political view" (Karagiannis, 2007, p. 5); a force that either sustains or disrupts social order in a general (e.g. human solidarity) or specific way (e.g. solidarity of specific individuals or organizations - e.g. universities).

In accordance, Juul (2013) argues that "solidarity is about coordinating social and cultural life chances in a socially just way", while Dean (1995) highlights that modern societies are in need of an inclusive concept of solidarity. They therefore develop a concept of reflective solidarity which goes beyond the already introduced affective (based on emotional relations) and conventional forms (based on common interests) of solidarity:

"At the universal level 'we' refers to 'we all' as solidarity members of an ideal communication community. What is expected is the recognition of our interdependency and shared vulnerability. The acknowledgement of our relationship to one another. At a time of increasing globalization, (im)migration and individualization, we have both the opportunity and the need to see differences of others as contributions to and aspects of the community of all of us." (Dean 1995, p. 136f.)

A non-exclusive concept of solidary is rooted in recognition (Juul, 2013). As Honneth (2001) stated, recognition is a prerequisite for prosperity, self-realization and a fully integrated society. Thus, a holistic approach that addresses questions of integration or cohesion has to bridge the micro and macro level. In explaining dynamics of social cohesion, the individual perception of recognition plays a crucial role. Individual expectations and social structures of opportunities both influence the potential for recognition. Honneth (2001) differentiates between three spheres of recognition: love, rights and solidarity. Through reciprocal recognition realized in social relations individuals get self-confidence (love). According to Honneth this manifestation of recognition in the form of emotional attention and support is the primary form of recognition on which others build. The sphere of rights tangles the mutual recognition as bearers of equal rights and duties, whereas in the sphere of solidarity the recognition of traits and competences of a subject are addressed. Therefore, it is about the feeling that accomplishments and contributions by the subject are recognized by others. Recognition is crucial for the self-images of individuals and promotes social integration. A lack of recognition becomes a source of societal disconnectedness. Recognition theories take subjective perceptions of reality as a starting point and go beyond objective criteria like integration in the job market, legal status etc. In accordance, social comparison processes are crucial parts of recognition. People tend to compare their endowments, their opportunities and to what extent their interests are taken seriously with the success of others. Perceptions of recognition therefore always include an evaluation of justice as well as relationships.

For this article, solidarity as well as recognition become empirical questions: what kind of bonds do the refugees who participate at MORE see between themselves, the universities and 
the (political) goal to become part of a new (host) society? Focusing on refugee students as well as incorporating the perspective of those who are teaching them and organizing the program makes it possible to understand solidarity and its limitations.

\section{The selected case study and methdology}

In September 2015, Universities Austria (uniko) - the umbrella organization of the 22 public universities - launched MORE, a program to integrate refugees and asylum seekers into universities (see https://uniko.ac.at/projekte/more), offering newly arrived migrants a possibility to (re-)join university life and tertiary education, providing opportunities beyond necessities like food, housing or medical help (Fiorioli, 2017). Offerings include language classes, academic courses, leisure activities like sports or hiking and a buddy program to foster social interaction. According to register data, the program was a success, counting more than 2000 participants. The average MORE student is 26 years old and male (90\%). The most prominent countries of origin are Syria and Afghanistan, followed by Iraq and Iran.

To discuss the question of solidarity within this project and how the participants view their lives as students while living as refugees in a foreign country, two main data sources are referenced. 1) Survey data: Former as well as current participants where surveyed using an online tool as well as a paper and pencil questionnaire within German language classes. The main focus was on evaluating the MORE initiative ( $\mathrm{n}=124$; see Prandner \& Moosbrugger, 2018). 2) Interview data: Building on the results of the survey in-depth interviews were conducted with seven participants, five so called internal experts (language trainers and administrative staff) and four external experts (caregivers and coaches). Guiding, open-ended questions targeted experiences and places of perceived recognition within and outside the educational context.

The next section gives a short overview on main findings of the survey, contextualizing the qualitative results. This is followed by the results of a focused, grounded theory based (Strauss \& Corbin, 1990) analysis of the interviews: 1) Application of thematical codes (open coding); 2) Constant comparison of findings (axial coding); 3) Identification of main themes (selective coding).

\section{Results of the case study}

By design MORE addresses a highly educated population. About $54 \%$ of the respondents hold a tertiary degree in their home country; another 17\% started one; and about $21 \%$ completed schooling, granting access to tertiary education. The reasons for participation are mainly intrinsic (e.g. because I want to learn new things). However, three out of four respondents see participation as an obligation (e.g. because I think I have to). Despite being 
in Austria for two years and four months on average, almost two out of three respondents have not received a decision on asylum yet. About $27 \%$ were granted asylum or subsidiary protection; $10 \%$ received a negative decision. To sum up: For a sizeable part of the sample the prospects of staying in Austria are insecure and more than half of the respondents consider participation somehow difficult. Yet, despite the difficulties to measure the objective impact of the program, $75 \%$ of the respondents are very satisfied with it, with more than $60 \%$ reporting that participation turned out to be an opportunity for them to develop friendships with Austrians (for a more detailed overview see Annex). Further analysis indicates that perception of satisfaction with the program as well as the perceived difficulty mainly relate to (4.1) emotional barriers, (4.2) available resources and (4.3) social/relational conditions.

\subsection{What is it like to study at an Austrian University? Experienced emotional barriers}

The qualitative part of the research further highlights the distress of the participants. High insecurity, barriers to participate and a migrant skeptical setting take their toll. Not only influencing participation, but constantly causing emotional distress. This is a recurring theme, nut only mentioned by the students themselves, but also by the involved experts:

"The main issue is that the process to gain asylum is lacking transpareny and their psychological situation is so troubled, that they have problems to focus on learning. These insecurities have a major impact on their chance for succeeding in their studies." (internal expert 2; quote translated from German)

"In my situation [...], as an asylum seeker, the question, if you can stay here is permanently on one's mind." (participant 6; quote translated from German)

Other existential needs play a role as well and refugee students are often reminded of their limited means:

"I'm afraid of my financial situation. [...] I desperately need to find work. [...] When I was thinking about starting to study, I had no idea if I could afford it or not. That was a big question." (participant 4; quote translated from German)

Despite these emotional burdens and drawbacks, students manage - in most cases - to keep up a positive mindset. This is of interest as it provides insights into the complex dynamics of intrinsic reasons for participating. As one interviewed expert puts it:

„What is common among them [...], probably [...] is their motivation, all of the $[M O R E]$ students have a very high motivation." (internal expert 1; quote translated from German)

Both, experts and participants, therefore value the MORE program, as it provides the refugees with some kind of stability and helps to migrate some of the emotional barriers and problems experienced. This ties to the fact that participating at e.g. university courses, doing homework or spending time on campus re-established a feeling of belonging. Here the solidarity offered 
by the universities and the staff taking care of the MORE students are seen as a chance for normalization, a prerequisite for rejoining society after prolonged traumatic experiences and a form of reflective solidarity (Dean, 1995). However, this process is tied to structural and even societal issues.

\subsection{Going beyond the university level? Resources and social structure}

As seen in the quotes before, solidarity is a concept that works on the societal level and is tied to social structure as a whole. Solidarity is about cultural and live chances (Juul, 2013). For the refugees in MORE, this is evident when it comes to their social status. On the one hand interviewees refer to a perceived demand, that refugees and asylum seekers need to integrate - commonly meaning that they should adapt to local customs - into the Austrian society. On the other hand, they highlight structural and social barriers, that make this nearly impossible. They range from material deprivation to social and systemic exclusion:

"Regarding lunch, I sometimes try to take a snack with me. I can't afford a sandwich at university. They are expensive. The cantina as well. If I take no snacks with me, I have to stay hungry, till I'm home." (participant 4; quote translated from German)

"We ask ourselves how things are at refugee homes. If it is possible to study well [...], when sharing quarters with other people. [...] Those things must be difficult, compared to our [regular] students." (internal expert 3; quote translated from German)

"When we [refugees] went to the playing field. [...] To play soccer. The others [Austrians] left. I could not understand it." (participant 7; quote translated from German)

"Until last year I tried to find some kind of activity, some volunteer work or whatever... But up to now I did not succeed or got an answer [...]. To have no meaningful task is the main problem." (participant 2; quote translated from German)

This is further complicated by the fact that asylum seekers are already excluded from most opportunities to participate in society, e.g.: find regular employment or even rent a flat. In this context the importance of a program like MORE becomes evident: Asylum seekers, as well as refugees get the chance to participate at university and have a structured opportunity to engage with others, learn the local language and further their knowledge. Therefore, $M O R E$ provides them with chances to lessen the impact of missing resources, as it offers free German classes, finances public transportation and a welcoming community. This goes along with the chance of recognition of traits and competences (Honneth, 2001).

\subsection{Rebuilding social relationships. Between understanding and prejudice}

Fleeing from one's country goes along with abandoning most social relationships. Refugees and asylum seekers have to rebuild their social networks once they settle in a host country. They are cut off from emotional attention and support, the primary source of recognition 
according to Honneth (2001). In this context interviewees not only stress that they are confronted with language barriers, but also with a high amount of skepticism:

"And yes, I think people here hate refugees. Most of them anyway. If I see two people talking and they are looking in my direction I assume they are talking about me." (participant 3, quote translated from German)

"If a refugee is doing something bad, all the people say that all the refugees are dangerous. This is really annoying." (participant 2, quote translated from German)

In this hostile environment building new relationships becomes a herculean task. Language barriers as well as structural barriers are hindering this process. Participants as well as experts stress this issue. MORE is described as a starting point for building up new social relations from where on other relationships may arise; a place where lecturers and organizational staff are aware of the problems the students experience regularly. This is accomplished by not offering only language and academic lectures, but also sports and group activities. However, the structure is limited in its efficiency.

\section{Conclusion}

Following our interview data, it can be stated that asylum seekers as well as refugees are in danger of not being recognized in Austrian society, while also having reduced opportunities for participation and gaining recognition. They describe their insecure asylum status causing emotional distress, as they are not knowing what the future holds. Therefore, it is hard for them to feel like equal members of society. Yet, some of the presented examples illustrate that the participants are willing to become part of the host society and are e.g. eager to study. However, existing barriers make it difficult to do so. Programs like MORE provide a partial solution to this. Participants stated that it helped establishing contacts between them and members of the Austrian host society and therefore provided a chance to gain recognition and get relevant insights into the underlying rules of the Austrian society, which were often seen as more formal than those found in their home countries. Additionally, university reestablishes a form of normality and it also integrates refugees and asylum seekers into an environment where solidarity - and not pity, to go back to Hannah Arendt (2006) - is seen as a suitable practice. Beyond that refugees are tasked with rebuilding meaningful social relationships. Concurrently they are experiencing prejudice, making this difficult as well. And here the limitations of the program become evident. Despite the fact that participants are stating that it helped them with their individual problems, systemic issues prevail. Overall, the interviewees are addressing a lack of solidarity also contradicting experiences are reported as well. MORE is perceived as an enabling chance, and therefore an example for reflective solidarity as stated by Dean (1995). It provides chances to recognize contributions of refugees to (a specific) community. 
Link to full Annex:

https://www.jku.at/fileadmin/gruppen/119/AES/Lehre/Lehrforschung/BA/suplementary m aterial PrandnerMoosbrugger_HigherEducationAndSolidarity.pdf

\section{References}

Arendt, H. (2006). On Revolution. New York: Penguin Books.

Bacher, J. (2017). Polarisierungstendenzen in Österreich: Ergebnisse einer latenten Klassenanalyse der Einstellungen zu Immigration. In F. Altenbrug, A. Faustmann, T. Pfeffer \& I. Skrivanek (eds.), Migration und Globalisierung in Zeiten des Umbruchs: Festschrift für Gudrun Biffl (pp. 379-397). Krems: Edition Donau-Universität.

Bacher, J., Fiorioli, E., Moosbrugger, R., Nnebedum, C., Prandner, D. \& Shovakar, N. (2019). Integration of refugees at universities: Austria's more initiative. Higher Education, online first. Retrieved on 22 January 2020 from https://link.springer.com/article/10.1007\%2Fs10734-019-00449-6

Dean, J. (1995). Reflective Solidarity. Constellations, 2(1), 114-140.

Durkheim, E. (1997). The Divission of Labor in Society. New York: The Free Press.

Fiorioli, E. (2017). Hochschulbildungsangebote für Geflüchtete. In S. Binder, \& G. Fartacek (Eds.), Facetten von Flucht aus dem Nahen und Mittleren Osten (Kultur- und Sozialanthropologie, 1st ed., pp. 213-226). Wien: facultas.

Honneth, A. (2001). Recognition or Redistribution? Changing Perspectives on the Moral Order of Society. Theory Culture \& Society, 18(2-3), 43-55.

Juul, S. (2013). Solidarity and Social Cohesion in Late Modernity: A Question of Recognition, Justice and Judgement in Situation. European Journal of Social Theory, 13(2), 253-269.

Karagiannis, N. (2007). Solidarity within Europe/Solidarity without Europe. European Societies, 9(1), 3-21.

Meyer, M. \& Simsa, R. (2018). Organizing the unexpected: How civil society organizations dealt with the refugee crisis. VOLUNTAS: International Journal of Voluntary and Nonprofit Organizations, 29(6), 1159-1175.

Prandner, D. \& Moosbrugger, R. (2018). Tertiary Education Opportunities for Refugees: MORE - Experiences and Insights, Linz: JKU. doi:10.11587/KVAZLN

Strauss, A. \& Corbin, J. (1990). Basics of qualitative research: Grounded theory procedures and techniques. Newburry Park: Sage.

Streitwieser, B., Loo, B., Ohorodnik, M. \& Jeong, J. (2018). Access for Refugees Into Higher Education: A Review of Interventions in North America and Europe. Journal of Studies in International Education, 21(2), 1-24. doi:10.1177/1028315318813201

Weber, M. (2006). Wirtschaft und Gesellschaft. Berlin: Verlag Zweitausendeins. 